\section{Public engagement and dialogic accounting through social media during COVID-19 crisis: a missed opportunity?}

\author{
Stefano Landi, Antonio Costantini, Marco Fasan and Michele Bonazzi \\ Department of Management, Ca' Foscari University of Venice, Venice, Italy
}

\begin{abstract}
Purpose - The purpose of this exploratory study is to investigate why and how public health agencies employed social media during coronavirus disease 2019 (COVID-19) outbreak to foster public engagement and dialogic accounting.

Design/methodology/approach - The authors analysed the official Facebook pages of the leading public agencies for health crisis in Italy, United Kingdom and New Zealand and they collected data on the number of posts, popularity, commitment and followers before and during the outbreak. The authors also performed a content analysis to identify the topics covered by the posts.

Findings - Empirical results suggest that social media has been extensively used as a public engagement tool in all three countries under analysis but - because of legitimacy threats and resource scarcity - it has also been used as a dialogic accounting tool only in New Zealand. Findings suggest that fake news developed more extensively in contexts where the public body did not foster dialogic accounting.

Practical implications - Public agencies may be interested in knowing the pros and cons of using social media as a public engagement and dialogic accounting tool. They may also leverage on dialogic accounting to limit fake news.

Originality/value - This study is one of the first to look at the nature and role of social media as an accountability tool during public health crises. In many contexts, COVID-19 forced for the first time public health agencies to heavily engage with the public and to develop new skills, so this study paves the way for numerous future research ideas.
\end{abstract}

Keywords COVID-19, Social media, Public engagement, Dialogic accounting

Paper type Research paper

\section{Introduction}

The ongoing digitalisation process of everyday life has increased communication channels and new opportunities for user participation to construct a shared discourse based on dialogic communication and a culture of participation (Jenkins, 2006).

Social media (SM) plays an essential role as an instrument of dialogic communication (Bonsón and Ratkai, 2013). Literature has shown that private and public organisations may employ SM to foster a two-way dialogue with citizens that triggers mutual learning processes and may induce both parties to revise their expectations (Bellucci and Manetti, 2017). In particular, in public organisations, appropriate SM use may contribute to public engagement, which involves encouraging citizens participation in public decisions (Rowe and Frewer, 2005; Manetti et al.,2017). Further, some authors suggested that SM has potential as a dialogic accounting tool, facilitating more participatory forms of decision-making and accountability

(C) Stefano Landi, Antonio Costantini, Marco Fasan and Michele Bonazzi. Published by Emerald Publishing Limited. This article is published under the Creative Commons Attribution (CC BY 4.0) licence. Anyone may reproduce, distribute, translate and create derivative works of this article (for both commercial and non-commercial purposes), subject to full attribution to the original publication and authors. The full terms of this licence may be seen at http://creativecommons.org/licences/by/4.0/ legalcode
Public engagement and dialogic accounting 
AAAJ 35,1 to stimulate transformative action and social change (Bellucci and Manetti, 2017; Bellucci et al., 2019).

Prior research has highlighted that dialogic tools promoting citizen-public agencies collaboration and engagement can help health crises management (French, 2011). In the coronavirus disease 2019 (COVID-19) epidemic, they are one of the non-pharmaceutical interventions implemented to contain the coronavirus spread (Haug et al., 2020). As many people turn to SM to obtain information and advice and discuss public policies, a dialogic approach to engagement can extend knowledge of the crisis, understand responsibilities, empower citizens in protecting from the virus and combat misinformation. This, in turn, can secure public trust and co-operation and influence the success of emergency response plans and measures (Han et al., 2020; Chen et al., 2020). However, although SM can be adopted to promote public engagement and dialogic interactions during health crises, this topic's research remains somewhat limited (Bonsón et al., 2019).

These considerations motivate this exploratory analysis, which aims at studying the nature of SM as an accountability tool employed by public health agencies during COVID-19 outbreak. It also studies the motivations that led public bodies to use such a tool, the public's reaction and, consequently, SM inherent and contingent limitations. We rely on previous literature on public engagement and dialogic accounting to interpret the public health agencies' communication content, citizens' reactions, and the evolution of interaction levels over time, consistently with the view that dialogic processes inform accountability relationships between organisations and stakeholders (Bebbington et al., 2007; Brown, 2009; Tanima et al., 2020). With this aim, we analyse Facebook posts of public health agencies operating in Italy, UK and New Zealand.

The empirical analysis of the interaction levels suggests that SM has been used as a public engagement tool in all of the three countries under analysis. Public health agencies used SM to disseminate information, receive users' feedback, and/or deploy emotional and operational support to citizens. Further, our results regarding posts content analysis and interaction level suggest that UK public health agencies did not deliberately use SM as a dialogic accounting tool. In Italy, instead, there has been a first attempt to generate dialogue and provide information in forms accessible to non-specialists to keep the decision-making process open. However, such an attempt failed probably because of the fear that organisations legitimacy would be damaged or lack of resources. Finally, the nature of SM for public agencies operating in NZ is that of a dialogic accounting tool that was successfully implemented.

The study extends previous research on SM and public engagement (Rowe and Frewer, 2005; Agostino and Arnaboldi, 2016), exploring how public health agencies have used SM to increase public engagement during the epidemic taking advantage of an international-based analysis. Further, the research contributes to the literature suggesting that SM represent a forceful mechanism to engage stakeholders in a dialogic conversation (e.g. Bellucci and Manetti, 2017). Specifically, it shows that in a context where conflicts that are inherent to a plural society may be strengthened by fear and anxiety, a dialogic approach in SM space can be used to address dissenting views and fake news, governing the flow of information that shapes the accountability relationship between public agencies and citizens. From this perspective, COVID-19 epidemic represented a missed opportunity for some public health agencies that do not engage in a dialogic approach to engagement through SM.

\section{Background}

\subsection{Public engagement during health emergencies: the potential role of social media}

Public engagement broadly refers to the practice of involving the citizens in public decisions and life, and is a persistent objective of public sector organisations (Rowe and Frewer, 2005). 
Public engagement can positively impact public governance, in terms of increased accountability and better-informed decision-making, strengthening societal cohesion, sense of community and trust in public administration (Manetti et al., 2017). Overall, public engagement requires specific initiatives, ranging from one-way information flows conveyed from public organisations to citizens, to two-way communication processes and knowledge exchanges (Agostino and Arnaboldi, 2016).

Literature has shown that public engagement is paramount in crisis management, as it improves the community's capacity to get through the different stages of an emergency effectively (Gálvez-Rodríguez et al., 2019). Specifically, during an epidemic, the nonpharmaceutical interventions' success to slow or hinder the spread of a virus relies heavily on citizens' compliance and co-operation (French, 2011; Han et al., 2020). The citizens' involvement through effective epidemic communication becomes crucial to mitigate public fear, foster trust in health authorities, and encourage adopting recommended behaviours (Chen et al., 2020). Public engagement is highly needed about the temporary measures that the public administrations may establish in anti-epidemic programmes and affect some community members more than others, such as social distancing and lockdowns (Garrett et al., 2009). It helps to ensure that programs incorporate the interests and values of different citizens segments (French, 2011).

Amongst the various tools available for public engagement, in recent years, public health agencies have increasingly adopted SM (Agostino and Arnaboldi, 2016; Bonsón et al., 2019). There are two main approaches to using SM during emergencies (Mori et al., 2020). A first approach involves a somewhat passive use, mostly aimed to disseminate information. A second approach is based on a systematic use as an emergency management tool, to deploy emotional and operational support to citizens through community outreach on public safety topics. Under this approach, SM can help public agencies to counteract information overload and faulty information.

Some empirical studies have focussed on how public health agencies use SM for increasing public engagement during an epidemic (Merchant et al., 2011; Seltzer et al., 2015; Guidry et al., 2017; Chen et al., 2020). They mostly evoke the potentialities of exploiting a dialogic approach to interact with the public via two-way communication flows.

\subsection{Dialogic accounting and social media}

The dialogic theory of engagement describes the attributes of a dialogic approach for addressing "limit situations", such as a societal problem involving different stakeholders (Bebbington et al., 2007). Dialogic engagement is an iterative process that starts from analysing the situation and consciousness regarding why a problem exists and requires consideration. It evolves through a process of dialogue, based on mutual trust, active listening, discussion and representation of problems and solutions. The dialogic interactions set the framework for practical testing of shared solutions and feed into a re-examination of the initial problem (Thomson and Bebbington, 2004). The outcome of dialogic engagement extends beyond two-way communication, as it activates mutual and dynamic learning processes that stimulate changes in the expectations and ideas of dialoguing parties, shared solutions to problems and inform accountability relationships between entities and stakeholders (Bebbington et al., 2007; Bellucci et al., 2019).

The dialogic theory of engagement acknowledges dialogic accounting as part of a broader package of initiatives aimed to promote organisations' accountability and participatory governance (Brown and Dillard, 2015a). Dialogic accounting broadly refers to accounting practices that are "responsive to the decision-making and accountability needs of a range of societal groups for use in organisational and civil society contexts" (Brown and Dillard, 2015b, p. 253). Brown (2009) has identified the fundamental principles of dialogic accounting: the need to recognise multiple ideological orientations, as people with different values and 
AAAJ

35,1

interests will seek to "account" differently for different things; to provide information in forms accessible to non-specialists (e.g. both quantitative and qualitative data, the use of narratives or visual tools); to ensure effective participatory processes; to be attentive to power relations; to avoid monetary reductionism; to recognise that there is no neutral and objective measurement. Dialogic accounting theorises accountability in terms of confrontations whereby "citizens exercise democratic rights over powerholders" (Tanima et al., 2020, p. 3), which links to the citizens' need to be informed on the achievements of an organisation's mission, actions and results (Pesci et al., 2020).

Although SM is not generally recognised as an accounting tool, it generally has "the potential to support dialogic accounting systems by providing valuable information on what stakeholders expect of each organisation in terms of quantitative or qualitative (narrative) information processing" (Bellucci and Manetti, 2017, p. 876). Only a few research works have explored the relationship between SM and dialogic accounting in the public sector field. They found that SM may be beneficial to dialogic engagement since it can help define what is material to stakeholders, collect their opinions, provide public information and reinforce a sense of belonging (e.g. Manetti et al., 2017).

In the context of a health crisis, public health agencies are accountable for crisis management and public health protection. According to the ethics of accountability, organisations should demonstrate that they fulfil their responsibility by giving an account (Baudot et al., 2020). Through SM, a dialogic accounting approach can enable public agencies to provide information accessible to citizens about the crisis and the countermeasures adopted to extend their knowledge and understand their responsibilities. Dialogic engagement through SM has the potential to promote mutual responsibility and reinforce accountability for actions taken, as citizens can exercise their right to be informed (Bellucci et al., 2019). Further, citizens are more likely to accept public agencies' difficult decisions if the decision-making processes are transparent, responsive and accountable (French, 2011). However, some scholars argue that organisations may communicate on SM more to improve their reputation and influence stakeholders' perceptions than for creating an authentic dialogue encouraging participatory processes and cooperation or for reasons tied to beliefs about responsibilities and accountabilities (Bellucci and Manetti, 2017; Deegan, 2019).

Further, besides its capability to support engagement processes, dialogic accounting also acknowledges that a "multi-voiced" society may include irreconcilable positions that cannot have a rational solution, and addresses areas of contestation assuming that they provide opportunities for value creation (Brown and Dillard, 2015a; Tregidga and Milne, 2020). In the context of a health crisis, these conflicts may be strengthened by fear and anxiety and exposure to misinformation (e.g. "infodemic" or "fake news"), which can undermine the crisis management by influencing and fragmenting social response (Cinelli et al., 2020). Further, they can be exacerbated in the SM virtual space due to rapidity of the information spread and the presence of "armchair epidemiologists" (Smith et al., 2020).

Based on these arguments, this study's exploratory research questions focus on the nature of SM as an accountability tool employed by public health agencies during COVID-19 outbreak. More specifically, the present analysis aims to investigate whether and why SM has been used as a mechanism to promote public engagement and/or as a dialogic accounting tool. By looking at the interaction types, it also aims at understanding the level of effectiveness of SM and its inherent and contingent limitations.

\section{Methodology}

We selected a purposive sample of three countries Italy, UK and New Zealand (NZ) to address the research questions. Italy was the first Western country to experience the epidemic onset. 
The UK has similar characteristics to Italy as having a (mainly public) national health system, and similar numbers for the epidemic (UK: 67 million people, 1.830.000 COVID-19 cases and 64,170 deaths; Italy: 60 million, $1.843 .000,64,520$ by 13 December 2020). Then, $\mathrm{NZ}$ was cited as a virtuous case of epidemic management regarding community engagement (Han et al., 2020). The Facebook page of the two most important public agencies for a health crisis was analysed for each country (see Table 1). To ensure that the correct official page was selected, we verified the direct link to the Facebook page on the official website. We focussed on Facebook because, together with Twitter, is one of the most used SM in these countries and previous research showed it is the most appropriate to publish and develop contents in a dialogic perspective that creates two-way, collaborative conversations with users (Manetti et al., 2017).

We designed a two-step analysis. First, we collected quantitative data regarding each page's communications and interactions pre- and post-COVID-19 onset, to analyse if and how public agencies changed their communication behaviour. Data were analysed via Fanpage Karma a web tool that allows obtaining the analytics of social networks pages (Mori et al., 2020). The data collected are the number of likes and comments on posts from each public agency account, and the number of posts per week. Then, based on Bonsón and Ratkai (2013) and Agostino and Arnaboldi (2016), these data were used to calculate three different metrics:

(1) Level of activity of each public health agency account. It was determined by counting the total number of posts for each week in the examined period.

(2) Commitment score (average number of comments per post $\times 1,000 /$ number of pages likes);

(3) Popularity score (average number of likes per post $\times 1,000 /$ number of pages likes).

Drawing upon Agostino and Arnaboldi (2016) measurement framework, we evaluate public engagement in terms of two dimensions, public communication and public participation. Public communication refers to the information flow in one direction, from local government to citizens. It is associated with popularity score because it measures the organisations' ability to broadcast information to a broad audience through SM. Public participation instead refers to the ability to build a two-way information flow between the public sector and citizens, creating public involvement (Rowe and Frewer, 2000). It can be measured with the commitment score since it captures aspects of interaction and dialogue.

As the second step, we performed a content analysis on the posts published in the first wave of COVID-19 (1 March-31 May 2020). The unit of analysis was each post generated by the agency on its official page in this period. In the first phase, a tentative coding scheme was developed based on the literature (Chen et al., 2020) and 20 random posts (for each page) discussed with all research team members. The discussion led to the definition of classification rules based on each category's contents and main keywords. Two authors used the coding rules to analyse posts. Then each author checked the $25 \%$ of coded posts. Any inconsistencies were solved by joint discussions amongst authors to reach an agreement. The authors are Italian mother tongue and have proficiency levels in English reading.

A total of 1,595 posts were manually analysed and categorised by their content as

(1) News about the disease evolution (number of people infected, hospitalized and recovered, live authorities press conference);

(2) Acknowledgements for healthcare professionals (or voluntary) at the frontline;

(3) Guidance for stakeholders (rules and practical indication about how to deal with the emergency); engagement and dialogic accounting 
AAAJ

35,1

40

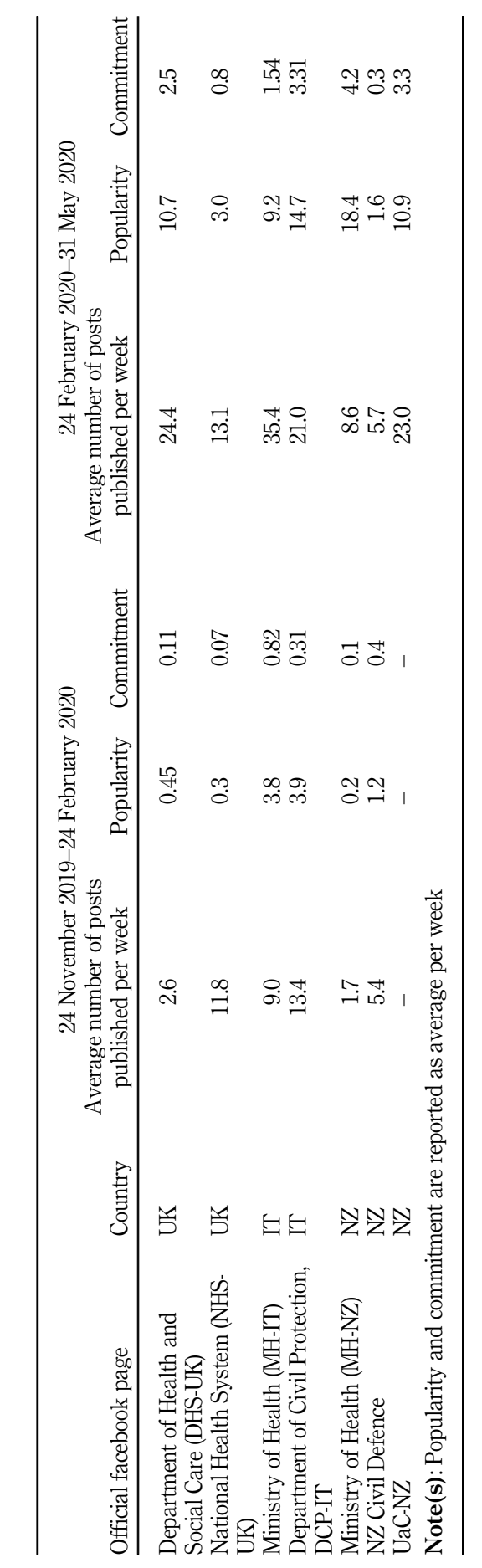

Table 1.

Number of Facebook posts, popularity and commitment pre- and post-COVID-19 onset 
(4) Information about government actions against COVID-19 (every post showing practical operation the organisation is running to fight epidemic);

(5) Information about international collaboration to face COVID-19 (posts showing actions or acknowledgements for help given/received by other countries);

(6) Contents not referred to COVID-19.

During the content investigation of NZ civil defence posts, we realised COVID-19 contents were only shares of another public official page called Unite against COVID-19 (UaC-NZ) hence added in the content analysis.

Moreover, to examine the SM contribution to public engagement in a system of dialogic accounting, we considered every comment/reply and assessed (1) the presence of interactions between agencies and citizens and the interactions amongst citizens through comments on official page posts and (2) the general tenor of the discussion. With this aim, drawing upon Bellucci and Manetti (2017) and Manetti et al. (2017), we computed two indexes:

(1) The "interaction ratio" that ranges between 1 (the public health agency replied or liked at least one user's comment in every post) and 0 (the agency did not reply or like any comment);

(2) The "Tenor of comments" index. To evaluate the discussion's tenor, we classified each comment with a value ranging from 1 (protest) to 5 (compliment). Comments with criticism received a value of 4 if they were constructive comments and 2 if they were only criticism per se. Then, the index was calculated as the average value for each post.

\section{Results}

Table 1 shows descriptive statistics for the pages for three months before and after COVID-19 onset. The analysis shows a significant increase in public agencies activity after the outbreak started. The only page not increasing its activity was NZ Civil defence. It did not develop a dedicated COVID-19 communication but only shared information from the UaC-NZ page.

To evaluate the different public engagement levels, we used the popularity and commitment scores, which adjust for the number of followers and the number of posts. Otherwise, it would be natural to observe higher engagement with higher activity. Popularity and commitment scores show that the level of activity grew, and that public communication and public participation increased. After COVID-19 onset, popularity was raised three times for MH-IT, five times for DCP-IT and over 10 times for the other pages. Commitment for MHIT almost doubled, while it raised from 0.31 to 3.31 for DCP-IT and tenfold or more for the other pages. The minor proportional increase in Italian pages is due to a higher starting point in both indicators. High and extensively increased public engagement levels are reported for all pages.

Interestingly, high activity levels do not always translate into higher public engagement levels in the same Country. For instance, MH-NZ has a lower activity level than UaC-NZ, but could get a higher level of popularity and commitment. MH-IT page had a higher activity level and popularity close to the DCP-IT's, but it attained a lower level of commitment. The cases confirm that publishing a large amount of information via Facebook does not automatically increase public engagement (Metallo et al., 2020). Citizens cannot absorb engagement in all the posts published by public organisations.

This study aims to provide details on what type of information public health agencies disclose on SM during the health crisis. As Table 2 shows, posts that provide information to citizens on actions to manage COVID-19 are the most common (44\%), followed by news on the 
AAAJ
35,1

42

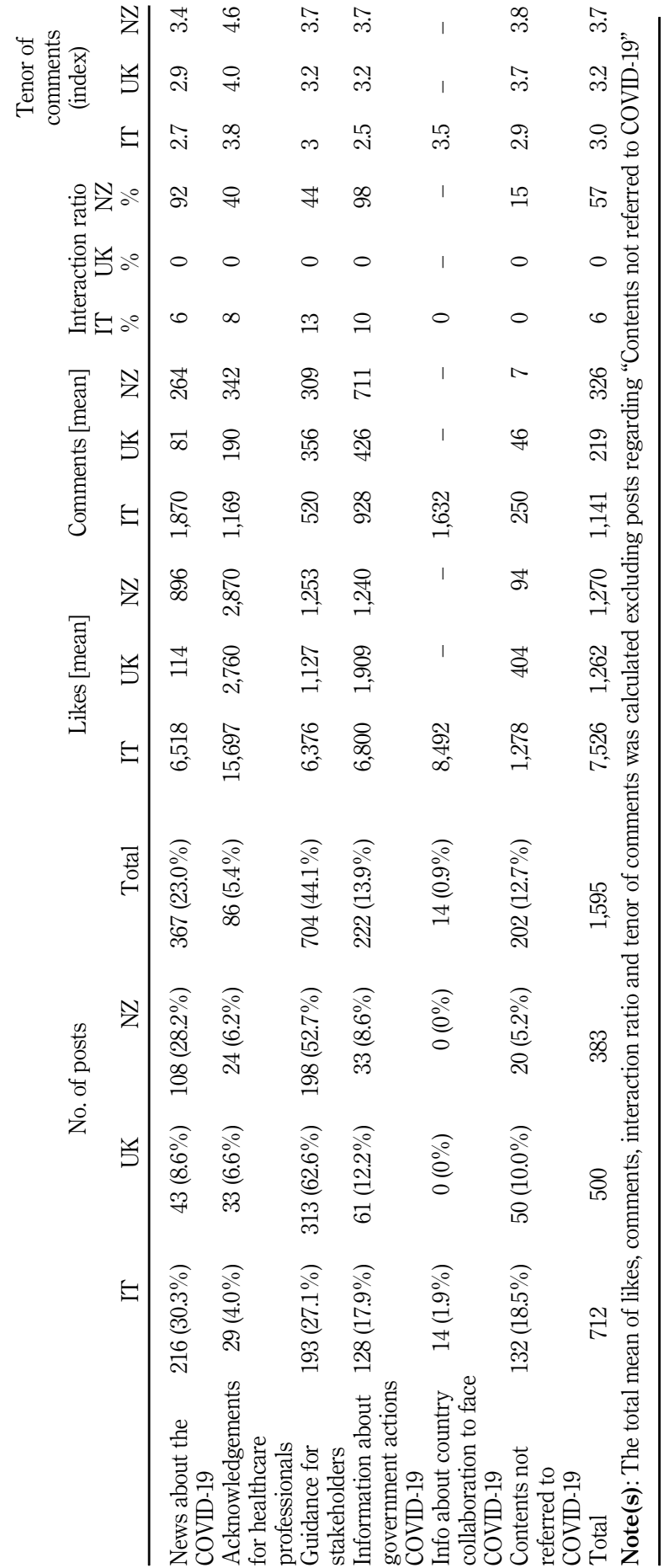

Table 2.

Content analysis results, level of interaction and tenor of comments/replies for each category 
outbreak spread in the Country $(23 \%)$ and information about government initiatives $(14 \%)$. Differences amongst countries emerge. UK public agencies are more willing to publish posts on "guidance for stakeholders" (62\%), a topic that on Italian pages have the same incidence to "news about COVID-19" (27\% vs 30\%). NZ is somewhere in between giving importance on "guidance for stakeholders" (53\%) while also informing on the epidemic evolution data (28\%). In particular, Italy and NZ in addressing the content "news about COVID" tend to use a calculative approach, reporting the number of people infected, hospitalized and recovered, together with public agency press conferences.

Common to all countries, acknowledgements for healthcare professionals reached more than the average number of likes and information about government actions received a high level of comments. Differently, Italy has a high level of public participation for "news about COVID" and low for "guidance stakeholders". The opposite is reported for UK and NZ.

Next, to deepen the engagement analysis under each post category, the replies posted by the public agencies and other users were considered. All the post categories related to the outbreak had a pile of users' comments, interacting amongst themselves. Almost under each post, there were comments and amongst users' replies to each comment. On the contrary, the interaction index amongst public agencies and users was significantly different amongst countries. The pages of UK public agencies never replied to user comments. Italian official pages replied to several comments in the first two weeks of March then they fell silent the rest of the time while NZ organisations reached a substantial and constant level of interaction ratio $(57 \%)$.

The "Tenor of comments" index shows the posts related to healthcare professionals' acknowledgements and information about country collaboration to face COVID-19 received positive feedback from users. Under this type of posts, even if some negative comment appeared, most comments display a sense of gratitude. News about COVID-19 had the more critical tenor of comments. Guidance for stakeholders and information about government actions have only slighter better tenors indicating that there were pure protest comments and few others with constructive criticism. The comments often are not directly related to the argument of the post and are mainly request of information or display sentiments of fear:

I have a question I have diabetes and have self-isolated and though I would be covered by my employer but am not on the extremely vulnerable list so does that mean I have to go back to work as I can't live on ssp what do I do.

I'm scared for my parents! My dad who's 77 has COPD and my mum is 72 she has to go out daily for shopping and pick up medicines when she's been told to self-isolate. They live 45 min drive from me in Braintree Essex, and I'm afraid they have known no one help them get their essentials. Can anyone help them?

There are also several comments of pure criticism:

Thanks for the numbers, I'm marking them all, so I can play them in the lottery ... . Because as you give the numbers, no one does.

You have always told lies... well after all you are part of your politicians. Miserable and clowns go home.

Interestingly, some citizens are calling for unity in the epidemic fight or telling their personal experience to those who report doubts:

The cashier from Brescia was 49 years old. The husband of a former colleague of mine who was hospitalized yesterday is 34 years old. So many young people get sick now!.

UK and Italy official pages did not regularly reply to users' comments. The lack of interaction between users and public health agencies did not hinder a continuous and sustained flow of

\section{engagement and dialogic accounting}

Public 
conversation amongst users themselves. For instance, several comments debated the "real existence" of the epidemic and other conspiracy theories:

....and this would be the terrible epidemic? It is a simple flu. The annual average of deaths from flu is of that order. Number similar to previous years.

Please clarify everything and explain once and for all what $5 \mathrm{G}$ is what they want to do I hear that they assemble antennas at night because we want to know the whole truth of everything.

NZ tried to steer the flow of information in a dialogic perspective. They answer over $90 \%$ of information requests and also of protests and faulty information. As the "Tenor of comments" index shows, this approach led to a lower number of these comments. Like in the UK and Italy, the conflictual comments were present, but were addressed replying to users:

Users: "We can't stop it (commercial activity) when so many businesses just doing what they want now liquor deliveries lockdowns a joke".

Page: "Hi there@name, if you have concerns about a business breaching the rules, you can visit [link to the content on government website]".

Users: "Is it true that there have been 61 suicides in NZ since this lockdown began and reaching 6 per day now?".

Page: “@name, this is not true. The Mental Health Foundation statement is that there is no evidence New Zealand's suicide rates have increase over lockdown. There is concern about the impact there rumours will have on people currently vulnerable to suicide [link]".

Users: "you don’t provide any data".

Page: "No official data is available yet. However, recently Police and Mental Health Foundation have spoken out about the issue [link to the content on the government website]. The evidence so far shows that callouts related to mental health have remained steady throughout this period. However, as mentioned, there's no official data available yet".

In most cases, the action-and-reaction ended in people thanking for the answer or even other users helping the page to replies to conflictual users. We found under NZ pages spontaneous comments like:

I just want to thank your social media team for having the patience of saints responding to some of the less kind people commenting here. Good grief.

\section{Discussion and conclusions}

In global health crises, effective public engagement is a critical non-pharmaceutical intervention tool aimed to protect and inform citizens, and SM is an essential medium to engage citizens (Han et al., 2020). The present study investigates how public agencies used SM during the epidemic. More specifically, drawing from public engagement and dialogic accounting literature, the study explores whether and how public agencies exploited its dialogic potentialities.

Results show that public agencies were generally successful in eliciting public engagement through SM during the COVID-19 outbreak as they made efforts to improve communication to keep informed and empowered citizens on the epidemic evolution. This is reflected in the steep increase in public communication and public participation and suggests that public agencies used SM to activate the accountability process, which also implies satisfying stakeholders' information needs (Pesci et al., 2020). These results align with the literature arguing that SM can be deployed during a health crisis to provide operational and emotional support, disseminating contents to reduce citizens' uncertainty and anxiety 
(French, 2011). The content analysis, which focusses on the main topics discussed by public agencies and citizens, supports this view. Public agencies mainly released information on the evolution of the epidemic, the correct behaviour to empower citizens in protecting from the virus and the actions taken to face the situation.

Despite this high level of public engagement, when we dig deeper, we find that dialogic communication has not taken off to the same extent in all three countries. Only public agencies operating in New Zealand managed SM virtual space from a dialogic accounting perspective. This result elicits reflections on the relationship between public engagement and dialogic accounting. The literature stated that stakeholder engagement processes could serve as essential dialogic accounting vehicles, and a dialogic approach can reinforce stakeholder engagement (Bellucci et al., 2019; Manetti et al., 2017). This work finds that, in the extreme context of an epidemic, public engagement is a necessary - but not sufficient - condition to trigger dialogic accounting.

From this perspective, COVID-19 epidemic represented a missed opportunity for some public health agencies to engage in a dialogue with the public through SM. We hypothesize that public agencies did not stimulate dialogic accounting because of two reasons.

First, to avoid possible damages to their organisational legitimacy. Any answer provided to users can be held accountable by users themselves, especially in an uncertain context such as the COVID-19 outbreak. This is consistent with the UK-based results, where public bodies never tried to engage in any dialogue with citizens.

Second, public agencies may not have engaged in any interaction because they did not have competencies or resources. Public agencies are still learning how to manage this tool effectively, and they still need to hire knowledgeable staff members to be ready to provide answers to citizens' questions and comments and eventually generate a dialogic accounting system. This second possible explanation is consistent with the evidence in the Italian case, where public bodies tried to engage in dialogue but only at the beginning of the epidemic when the workload was relatively lower in terms of SM activity. Future research may further explore - for instance, through case studies - the nature of such barriers hindering SM utilization as a dialogic accounting tool.

Our results are also suggesting that SM is not always inherently beneficial as it may cause the rapid spread of misinformation ("fake news"). During a health crisis - when emotions run high - conflicts may be strengthened by fear and anxiety and exposure to misinformation, which can compromise the crisis management (Cinelli et al., 2020). For instance, several comments debated the "real existence" of the epidemic and other conspiracy theories. According to previous studies (see Sorensen et al., 2015), real and fake news blend together to the greater extent according to one's own capabilities, influenced by cognitive biases, lack of willingness to fact check, rarely adequate digital literacy, and incohesive or absent health literacy.

Literature shows that official SM channels can be beneficial to public administration in reducing fake news (Mori et al., 2020). Nevertheless, public agencies' mere presence on SM is not enough to hit the target, and researchers have emphasised the importance of appropriate use of SM to promote public engagement for handling health crises (Chen et al., 2020; Han et al., 2020).

Our results show that public agencies establishing an active dialogic communication have a higher level of the tenor of comments index, with a lower incidence of contestation or posts reporting fake news. In this sense, during a health crisis, a dialogic approach to engagement can steer information flow and represent a possible antidote to the growth of antagonistic behaviours proper of conspiracy theorists or "armchair epidemiologists". In other words, consistently with Brown (2009), it seems that dialogic accounting can transform antagonism into agonism. 
AAAJ

35,1

46

\section{References}

Agostino, D. and Arnaboldi, M. (2016), "A measurement framework for assessing the contribution of social media to public engagement: an empirical analysis on Facebook", Public Management Review, Vol. 18 No. 9, pp. 1289-1307.

Baudot, L., Dillard, J. and Pencle, N. (2020), "Hybrid organizations and an ethic of accountability: the role of accountability systems in constructing responsible hybridity", Accounting, Auditing \& Accountability Journal, Vol. ahead-of-print No. ahead-of-print, doi: 10.1108/AAAJ-11-2019-4287.

Bebbington, J., Brown, J., Frame, B. and Thomson, I. (2007), "Theorizing engagement: the potential of a critical dialogic approach", Accounting, Auditing \& Accountability Journal, Vol. 20 No. 3, pp. 356-381.

Bellucci, M. and Manetti, G. (2017), "Facebook as a tool for supporting dialogic accounting? Evidence from large philanthropic foundations in the United States", Accounting, Auditing \& Accountability Journal, Vol. 30 No. 4, pp. 874-905.

Bellucci, M., Simoni, L., Acuti, D. and Manetti, G. (2019), "Stakeholder engagement and dialogic accounting: empirical evidence in sustainability reporting", Accounting, Auditing \& Accountability Journal, Vol. 32 No. 5, pp. 1467-1499.

Bonsón, E. and Ratkai, M. (2013), "A set of metrics to assess stakeholder engagement and social legitimacy on a corporate Facebook page", Online Information Review, Vol. 37 No. 5, pp. 787-803.

Bonsón, E., Perea, D. and Bednárová, M. (2019), "Twitter as a tool for citizen engagement: an empirical study of the Andalusian municipalities", Government Information Quarterly, Vol. 36 No. 3, pp. $480-489$.

Brown, J. (2009), "Democracy, sustainability and dialogic accounting technologies: taking pluralism seriously", Critical Perspectives on Accounting, Vol. 20 No. 3, pp. 313-342.

Brown, J. and Dillard, J. (2015a), "Dialogic accountings for stakeholders: on opening up and closing down participatory governance”, Journal of Management Studies, Vol. 52 No. 7, pp. 961-985.

Brown, J. and Dillard, J. (2015b), "Opening accounting to critical scrutiny: towards dialogic accounting for policy analysis and democracy", Journal of Comparative Policy Analysis, Vol. 17 No. 3, pp. 247-268.

Chen, Q., Min, C., Zhang, W., Wang, G., Ma, X. and Evans, R. (2020), "Unpacking the black box: how to promote citizen engagement through government social media during the COVID-19 crisis", Computers in Human Behavior, Vol. 110, pp. 1-11.

Cinelli, M., Quattrociocchi, W., Galeazzi, A., Valensise, C.M., Brugnoli, E., Schmidt, A.L., Zola, P., Zollo, F. and Scala, A. (2020), "The COVID-19 social media infodemic", Nature Scientific Reports, Vol. 10 No. 16598, pp. 1-10.

Deegan, C.M. (2019), "Legitimacy theory - despite its enduring popularity and contribution, time is right for a necessary makeover", Accounting, Auditing \& Accountability Journal, Vol. 32 No. 8, pp. 2307-2329.

French, P.E. (2011), "Enhancing the legitimacy of local government pandemic influenza planning through transparency and public engagement”, Public Administration Review, Vol. 71 No. 2, pp. 253-264.

Gálvez-Rodríguez, M.d.M., Haro-de-Rosario, A., García-Tabuyo, M. and Caba-Pérez, C. (2019), "Building online citizen engagement for enhancing emergency management in local European government: the case of the November 2015 Paris attacks", Online Information Review, Vol. 43 No. 2, pp. 219-238.

Garrett, J.E., Vawter, D.E., Prehn, A.W., DeBruin, D.A. and Gervais, K.G. (2009), "Listen! the value of public engagement in pandemic ethics", The American Journal of Bioethics, Vol. 9 No. 11, pp. 17-19.

Guidry, J.P.D., Jin, Y., Orr, C.A., Messner, M. and Meganck, S. (2017), "Ebola on Instagram and Twitter: how health organizations address the health crisis in their social media engagement", Public Relations Review, Vol. 43 No. 3, pp. 477-486. 
Han, E., Tan, M.M.J., Turk, E., Sridhar, D., Leung, G.M., Shibuya, K., Asgari, N., Oh, J., Garcìa-Basteiro, A.L., Hanefeld, J., Cook, A.R., Hsu, L.Y., Teo, Y.Y., Heymann, D., Clark, H., McKee, M. and LegidoQuigley, H. (2020), "Lessons learnt from easing COVID-19 restrictions: an analysis of countries and regions in Asia Pacific and Europe", The Lancet, Vol. 396 No. 10261, pp. 1525-1534.

Haug, N., Geyrhofer, L., Londei, A., Dervic, E., Desvars-Larrive, A., Loreto, V., Pinior, B., Thurner, S. and Klimek, P. (2020), "Ranking the effectiveness of worldwide COVID-19 government interventions", Nature Human Behaviour, Vol. 4, pp. 1303-1312.

Jenkins, H. (2006), Convergence Culture: When Old and New Media Collide, New York University Press, New York, NY.

Manetti, G., Bellucci, M. and Bagnoli, L. (2017), "Stakeholder engagement and public information through social media: a study of Canadian and American public transportation agencies", The American Review of Public Administration, Vol. 47 No. 8, pp. 991-1009.

Merchant, R.M., Elmer, S. and Lurie, N. (2011), "Integrating social media into emergency-preparedness efforts”, The New England Journal of Medicine, Vol. 365 No. 4, pp. 289-291.

Metallo, C., Gesuele, B., Guillamòn, M.-D. and Rìos, A.-M. (2020), "Determinants of public engagement on municipal Facebook pages", The Information Society, Vol. 36 No. 3, pp. 147-159.

Mori, E., Barabaschi, B., Cantoni, F. and Virtuani, R. (2020), "Local governments' communication through Facebook-evidences from COVID-19 pandemic in Italy", Journal of Public Affairs, Vol. e2551, pp. 1-14.

Pesci, C., Costa, E. and Andreaus, M. (2020), "Using accountability to shape the common good", Critical Perspectives on Accounting, Vols 67-68, pp. 1-14.

Rowe, G. and Frewer, L.J. (2000), "Public participation methods: a framework for evaluation", Science, Technology and Human Values, Vol. 25 No. 1, pp. 3-29.

Rowe, G. and Frewer, L.J. (2005), “A typology of public engagement mechanisms”, Science, Technology and Human Values, Vol. 30 No. 2, pp. 251-290.

Seltzer, E.K., Jean, N.S., Kramer-Golinkoff, E., Asch, D.A. and Merchant, R.M. (2015), "The content of social media's shared images about Ebola: a retrospective study", Public Health, Vol. 129 No. 9, pp. 1273-1277.

Sørensen, K., Pelikan, J.M., Röthlin, F., Ganahl, K., Slonska, Z., Doyle, G., Fullam, J., Kondilis, B., Agrafiotis, D., Uiters, E., Falcon, M., Mensing, M., Tchamov, K., van den Broucke, S. and Brand, H. (2015), "Health literacy in Europe: comparative results of the European health literacy survey (HLS-EU)", European Journal of Public Health, Vol. 25 No. 6, pp. 1053-1058.

Smith, G.D., Blastland, M. and Munafò, M. (2020), “Covid-19's known unknowns”, The BMJ, Vol. 371, p. m3979.

Tanima, F.A., Brown, J. and Dillard, J. (2020), "Surfacing the political: women's empowerment, microfinance, critical dialogic accounting and accountability", Accounting, Organizations and Society, Vol. 85, p. 101141.

Thomson, I. and Bebbington, J. (2004), “It doesn't matter what you teach?”, Critical Perspectives on Accounting, Vol. 15 Nos 4-5, pp. 609-628.

Tregidga, H. and Milne, M.J. (2020), "Not at our table: stakeholder exclusion and ant/agonistic engagements", Critical Perspectives on Accounting, in press, doi: 10.1016/j.cpa.2020.102265.

\section{Corresponding author}

Antonio Costantini can be contacted at: antonio.costantini@unive.it

For instructions on how to order reprints of this article, please visit our website:

www.emeraldgrouppublishing.com/licensing/reprints.htm

Or contact us for further details: permissions@emeraldinsight.com 